Miguel Pais Moreira Lopes

\title{
O processo de elaboração de resumos acadêmicos: Uma análise com base em modelos processuais da escritura e gêneros textuais
}

Dissertação apresentada como requisito parcial para obtenção do grau de Mestre pelo Programa de Pós-Graduação em Letras do Departamento de Letras do Centro de Teologia e Ciências Humanas da PUC-Rio.

Orientadora: Profa. Erica dos Santos Rodrigues 
Miguel Pais Moreira Lopes

O processo de elaboração de resumos acadêmicos: uma análise com base em modelos processuais da escritura e gêneros textuais

Dissertação apresentada como requisito parcial para obtenção do grau de Mestre pelo programa de Pós-Graduação em Letras do Departamento de Letras do Centro de Teologia e Ciências Humanas da PUC-Rio. Aprovada pela Comissão Examinadora abaixo assinada.

\author{
Profa. Erica dos Santos Rodrigues \\ Orientadora \\ Departamento de Letras - PUC-Rio
}

Profa. Violeta de San Tiago Dantas

Barbosa Quental

Departamento de Letras - PUC-Rio

Profa. Maria Cristina Lobo Name

UFJF

Profa. Denise Berruezo Portinari Coordenadora Setorial do Centro de Teologia e Ciências Humanas - PUC-Rio

Rio de Janeiro, 01 de abril de 2011. 
Todos os direitos reservados. É proibida a reprodução total ou parcial do trabalho sem a autorização da universidade, do autor e do orientador.

\section{Miguel Pais Moreira Lopes}

Graduou-se em Letras - Tradução (Inglês-Português) na PUCRio, RJ; atua na linha de pesquisa "A leitura e a produção escrita numa abordagem psicolinguística: demandas cognitivas e especificidades de processamento".

Ficha Catalográfica

Lopes, Miguel Pais Moreira

O processo de elaboração de resumos acadêmicos: uma análise com base em modelos processuais da escritura e gêneros textuais / Miguel Pais Moreira Lopes; orientadora: Erica dos Santos Rodrigues. - 2011.

147 f. : il. ; $30 \mathrm{~cm}$

Dissertação (mestrado) - Pontifícia Universidade Católica do Rio de Janeiro, Departamento de Letras, 2011. Inclui bibliografia

1. Letras - Teses. 2. Psicolinguística. 3. Modelos processuais da escritura. 4. Revisão textual. 5. Gêneros textuais. 6. Resumo acadêmico. I. Rodrigues, Erica dos Santos. II. Pontifícia Universidade Católica do Rio de Janeiro. Departamento de Letras. III. Título. 


\section{Agradecimentos}

Aos meus pais, por sempre investirem em mim e acreditarem no meu potencial,

A Thaís, por me completar e não permitir que eu desista,

À minha orientadora, Erica Rodrigues, pelo olhar atento e cuidadoso, exemplo profissional e estimada amizade,

A todos os professores da graduação e do mestrado, por me capacitarem a ser o profissional que sou hoje,

Aos meus colegas de graduação e pós, com quem troquei experiências e ideias valiosas à minha formação,

Aos professores Paulo Henriques Britto e Patrícia Corado, pelo constante incentivo e exemplos inspiradores,

Às professoras Helena Martins, Inês Miller, Barbara Hemais e Violeta Quental pelas valiosas observações e ajudas ao longo do Mestrado,

Aos professores que participaram da Comissão Examinadora,

À CAPES e à PUC-Rio, pelos auxílios concedidos, sem as quais este trabalho não poderia ter sido realizado. 


\section{Resumo}

Lopes, Miguel Pais Moreira; Rodrigues, Erica dos Santos. O processo de elaboração de resumos acadêmicos: uma análise com base em modelos processuais da escritura e gêneros textuais. Rio de Janeiro, 2011. 147p. Dissertação de Mestrado - Departamento de Letras, Pontifícia Universidade Católica do Rio de Janeiro.

Este trabalho visa investigar o processo de produção e revisão textuais de resumos acadêmicos na graduação através de uma reflexão teórica pautada em gêneros textuais e modelos processuais da escritura. Levamos em conta como os alunos realizam a sumarização, que operações línguísticas e estratégias de produção são mais utilizadas, com que conceito de revisão têm trabalhado e até que ponto esses fatores influenciam a qualidade textual. A escrita de textos acadêmicos tem se mostrado um desafio a universitários de todas as áreas, cada vez mais despreparados para o manejo dos diferentes gêneros nesse âmbito. Dentre esses, destaca-se o resumo, cujo domínio torna-se imprescindível por pressupor uma série de habilidades básicas de leitura e escrita. A metodologia adotada consiste numa análise de dados a partir de uma atividade escrita de produção de resumos realizada com dois grupos de alunos e que faz uso da ferramenta computacional Camtasia Studio. A estruturação dos resumos refletiu a organização discursiva do original. Os alunos fizeram amplo uso de paráfrase, cuja manifestação ocorreu predominantemente sob forma de sinonímia e alterações sintáticas. A sumarização foi marcada por diversos apagamentos, na maioria de orações consideradas acessórias (adjetivas e adverbiais), refletindo parcialmente o critério de extração de sumarizadores eletrônicos. Em boa parte, as proposições tomadas como mais relevantes corresponderam aos tópicos frasais do original e foram mais facilmente reconhecidas quando expressas em ordem direta e numa posição previsível. A revisão revelou predomínio de um processamento monitorado da escrita, com operações de revisão sendo executadas durante a produção.

\section{Palavras-chave}

Psicolinguística; modelos processuais da escritura; revisão textual; Gêneros Textuais; resumo acadêmico 


\section{Abstract}

Lopes, Miguel Pais Moreira; Rodrigues, Erica dos Santos (Advisor). The process of writing academic summaries: an analysis based on writing process models and textual genres. Rio de Janeiro, 2011. 147p. MSc. Dissertation - Departamento de Letras, Pontifícia Universidade Católica do Rio de Janeiro.

This research aims at investigating the process of writing and revising academic summaries in grad courses by focusing on fundamental concepts in textual genres and writing process models. We considered how students perform summarization, which linguistic features and production strategies they use the most, which concepts of revision they have, and to what extent these factors influence the text's quality and effectiveness. Academic writing has proven to be a challenge among university students, who, regardless of their field, seem less and less prepared to cope with the different genres in grad contexts. The academic summary is a genre that stands out in this regard, since it involves mastering a set of basic reading and writing abilities required in the writing of more complex genres. The methodology is based on an analysis of data obtained from a writing activity regarding summary writing carried out with two groups of students and with the use of the Camtasia Studio software. Summaries' structuring was similar to the source text's discursive organization. Students used lots of paraphrasing, mainly through synonyms and syntactic modifications. Summarization was characterized by lots of deletions, mostly clauses that are considered accessorial (adjective and adverbial), thus partly reflecting electronic summarization extraction patterns. Generally, propositions that were considered the most relevant matched the source text's phrasal topics and were more easily recognized when written in direct order and appearing in a predictable position. Revision as a monitored writing process prevailed as a concept, with revision operations being performed during text production.

\section{Keywords}

Psycholinguistics; writing process models; revision; Textual Genres; academic summary 


\section{Sumário}

1. Introdução 11

2. Gêneros textuais: pressupostos teóricos 14

2.1. O resumo acadêmico: características fundamentais 16

2.2. A atividade de sumarização 18

2.3. Sumarização eletrônica: algumas considerações 23

$\begin{array}{ll}\text { 2.4. O papel da leitura } & 27\end{array}$

3. O processamento da escrita: modelos e reflexões 31

3.1. O modelo de Hayes \& Flower (1980) 31

3.2. Os modelos de Bereiter \& Scardamalia (1987) 36

3.3. Outros modelos e temas relevantes 42

3.4. A proposta de Garcez (2004) 49

3.5. A revisão como etapa processual 52

4. Metodologia de pesquisa e análise dos dados 57

4.1. Proposta de atividade com resumos 58

4.2. Organização e classificação dos dados $\quad 60$

4.2.1. Análise da macroestrutura textual 61

4.2.2. Processo de sumarização $\quad 66$

4.2.3. Análise das operações de produção e revisão 73

4.2.4. Quantificação de voltas ao texto e pausas 91

4.2.5. Estratégias de produção e revisão 96

4.2.6. Atitudes para com a etapa de revisão 100

4.2.7. Síntese dos dados obtidos 101

4.3. Análise e interpretação dos dados 107

5. Considerações finais 113

6. Referências bibliográficas 116

Anexo 1 - Texto e instruções para atividade escrita 120

Anexo 2 - Registro descritivo da produção dos alunos 121

Anexo 3 - Confronto entre os resumos e as macroproposições 137

Anexo 4 - Divisão do texto em proposições e ações dos alunos 144 


\section{Índice de figuras e tabelas}

Figura 1 - Modelo de Hayes \& Flower (1980) para o processamento da escrita

Figura 2 - Modelo revelador de conhecimento (BEREITER \& SCARDAMALIA, 1987)

Figura 3 - Modelo de transformação do conhecimento (BEREITER \& SCARDAMALIA, 1987)

Figura 4 - Esquematização proposta por Garcez para o processamento da escrita

Figura 5 - Modelo para o processo de revisão proposto por Hayes et al. (1987)

Tabela 1 - Comportamento dos alunos em relação às macroproposições

Tabela 2 - Distribuição de critérios por aluno

Tabela 3 - Distribuição de resultados por macroproposição

Tabela 4 - Descrição de operações de paráfrase

Tabela 5 - Quantificação das operações de sumarização por aluno

Tabela 6 - Quantificação das operações de sumarização por proposição

Tabela 7 - Distribuição das operações de A1

Tabela 8 - Distribuição das operações de A2

Tabela 9 - Distribuição das operações de A3

Tabela 10 - Distribuição das operações de B1

Tabela 11 - Distribuição das operações de B2

Tabela 12 - Distribuição das operações de B3

Tabela 13 - Mapeamento de pausas e voltas ao texto de A1 (Grupo A)

Tabela 14 - Mapeamento de pausas e voltas ao texto de A2 (Grupo A)

Tabela 15 - Mapeamento de pausas e voltas ao texto de A3 (Grupo A)

Tabela 16 - Mapeamento de pausas e voltas ao texto de B1 (Grupo B)

Tabela 17 - Mapeamento de pausas e voltas ao texto de B2 (Grupo B)

Tabela 18 - Mapeamento de pausas e voltas ao texto de B3 (Grupo B)

Tabela 19 - Estratégias de produção e revisão de resumos 96

Tabela 20 - Mapeamento do uso de estratégias

de produção e revisão - Grupo A

Tabela 21 - Mapeamento do uso de estratégias de produção

e revisão - Grupo B

Tabela 22 - Quantificação do número de vezes que cada estratégia foi utilizada 
"Certo não, quando ao catar palavras: a pedra dá à frase seu grão mais vivo: obstrui a leitura fluviante, flutual, açula a atenção, isca-a como o risco".

João Cabral de Melo Neto, Catar feijão 